\title{
ANALISIS BIAYA PEMANENAN DAN PRODUKTIVITAS PRODUKSI KAYU EKALIPTUS (STUDI KASUS: HPHTI PT.PSPI DISTRIK PETAPAHAN)
}

\author{
(Analysis of Harvesting Costs and Productivity of Eucalyptus Wood Production \\ Case Study: HPHTI PT.PSPI Petapahan District) \\ Jesica Santa Fermana ${ }^{1}$, Emy Sadjati ${ }^{2}$, Muhammad Ikhwan ${ }^{2}$ \\ ${ }^{1}$ Fakultas Kehutanan Universitas Lancang Kuning \\ ${ }^{2}$ Staff Pengajar Fakultas Kehutanan Universitas Lancang Kuning \\ Jln. Yos Sudarso KM.08 Rumbai, Pekanbaru \\ E-mail: jesicasantafermana1554251033@gmail.com,emy_mnhunilak@gmail.com, \\ mmighwan@yahoo.com
}

Diterima: 18 November 2019, Direvisi: 09 Desember 2019, Disetujui: 31 Desember 2019

DOI: https://doi.org/10.31849/forestra

\begin{abstract}
Industrial plantations are production forests that have monoculture species (1 species), which take up to 5 years to be ready for harvest. Before harvesting, activities are carried out it is necessary to analyze the cost of harvesting, where the aim is to find out the magnitude of the profits obtained by the company. The purpose of this study is to analyze the cost of harvesting and analyze the productivity of wood from harvesting activities at HPHTI PT. PSPI Petapahan District. This research was conducted in May - June 2019. The sampling method in this study used a purposive sampling system. Based on the results of research conducted at PT. PSPI Petapahan District, the production costs for harvesting are activity are obtained, the amount of costs for felling and dividing the stems of IDR 27.235/hour, the costs for stacking IDR 200.584/hour, costs for stripping bark of IDR 203.991/hour, costs for skidding IDR 204.091/hour, the fee for loading and unloading skid is IDR 200.584/hour and the cost for loading to truck is IDR 200.584/hour. While harvesting productivity for each activity is felling productivity of 20,97 $\mathrm{m}^{3} /$ hour, division of stems of $35,25 \mathrm{~m}^{3} /$ hour, stacking of $21,10 \mathrm{~m}^{3} /$ hour, stripping bark of $39,50 \mathrm{~m}^{3} /$ hour, skidding of wood by $21,23 \mathrm{~m}^{3} /$ hour, skid loading and unloading of 49,61 $\mathrm{m}^{3} /$ hour and loading to trucks of $12,40 \mathrm{~m}^{3}$ /hour.
\end{abstract}

Keywords: Analysis of harvest costs, PT. PSPI District Petapahan, Wood Productivity

Jesica S.F, Emy Sadjati, Muhammad Ikhwan/Wahana Forestra: Jurnal Kehutanan Vol 14 No 02/2019 38 


\begin{abstract}
ABSTRAK
Hutan tanaman industri (HTI) adalah hutan produksi yang memiliki jenis tanaman monokultur (1 jenis), dimana membutuhkan waktu hingga 5 tahun sampai tanaman tersebut siap untuk dipanen. Sebelum kegiatan pemanenan dilakukan maka perlu analisis biaya pemanenan, dimana tujuannya untuk mengetahui besarnya keuntungan yang diperoleh oleh perusahaan. Adapun tujuan dari penelitian ini adalah untuk menganalisis biaya pemanenan serta menganalisis produktivitas kayu dari kegiatan pemanenan di HPHTI PT. PSPI Distrik Petapahan. Penelitian ini dilakukan pada bulan Mei - Juni 2019. Metode pengambilan contoh pada penelitian ini menggunakan sistem purposive sampling. Berdasarkan hasil penelitian yang dilakukan di PT. PSPI Distrik Petapahan, maka diperoleh biaya produksi untuk pemanenan setiap kegiatan adalah besarnya biaya untuk penebangan dan pembagian batang sebesar Rp 27.235/jam, biaya untuk penumpukan sebesar Rp 200.584/jam, biaya untuk kupas kulit sebesar Rp 203.991/jam, biaya untuk penyaradan sebesar Rp 204.091/jam, biaya untuk bongkar muat sarad sebesar Rp 200.584/jam dan biaya untuk pemuatan ke truk sebesar Rp 200.584/jam. Sementara produktivitas pemanenan setiap kegiatan adalah produktivitas penebangan sebesar $20,97 \mathrm{~m}^{3} / \mathrm{jam}$, pembagian batang sebesar $35,25 \mathrm{~m}^{3} / \mathrm{jam}$, penumpukan sebesar $21,10 \mathrm{~m}^{3} / \mathrm{jam}$, pengupasan kulit sebesar $39,50 \mathrm{~m}^{3} / \mathrm{jam}$, penyaradan sebesar 21,23 $\mathrm{m}^{3} / \mathrm{jam}$, bongkar muat sarad sebesar 49,61 $\mathrm{m}^{3} / \mathrm{jam}$ dan pemuatan ke truk sebesar $12,40 \mathrm{~m}^{3} / \mathrm{jam}$.
\end{abstract}

Kata Kunci: Analisis Biaya Pemanenan, PT. PSPI Distrik Petapahan, Produktivitas Kayu

\section{PENDAHULUAN}

Hutan tanaman industri (HTI) adalah hutan produksi yang memiliki jenis tanaman monokultur (1 jenis). Di Provinsi Riau sendiri jenis dominan yang ditanam adalah ekaliptus, yang membutuhkan waktu sekitar 5 tahun sampai kayu tersebut siap untuk dipanen. Pengelolaan hutan tanaman industri memiliki tahapan yang sama dengan hutan tanaman pada umumnya, yaitu dimulai dari penyiapan benih sampai pada akhirnya kayu tersebut dipanen. Pemanenan hasil hutan merupakan suatu usaha pemanfaatan kayu dengan mengubah tegakan pohon berdiri menjadi sortimen kayu bulat dan dikeluarkan dari hutan untuk kemudian dimanfaatkan sesuai dengan peruntukannya. Kegiatan pemanenan hasil hutan di HTI dimulai dari penebangan, pembagian batang, penumpukan, pengupasan kulit, penyaradan dan pemuatan. Dalam kegiatan pemanenan kayu, hal yang perlu diperhatikan adalah arah rebah yang benar sehingga pemanfaatan kayu lebih efisien dan biaya yang dikeluarkan menjadi lebih rendah. Pemanenan hasil hutan yang dilakukan di hutan tanaman industri memiliki tujuan untuk mengoptimalkan pasokan kayu industri, memaksimalkan nilai kayu serta meningkatkan nilai tambah bagi pihak 
perusahaan dan juga devisa Negara.

Peningkatan nilai tambah bagi pihak perusahaan dapat dilihat dari hasil analisis biaya pemanenan. Berdasarkan analisis biaya pemanenan tersebut maka dapat dilihat tingkat efisiensi dari kegiatan pemanenan yang dilakukan oleh pihak perusahaan HTI.

Analisis biaya pemanenan ini dilakukan untuk mengetahui besarnya tingkat produktivitas dari pemanenan kayu di HTI. Hal tersebut dapat diketahui dari besarnya biaya-biaya yang dikeluarkan oleh perusahaan untuk kegiatan pemanenan serta besarnya produktivitas dari kegiatan pemanenan tersebut. Hal ini diperlukan bagi pihak perusahaan untuk mengukur waktu yang optimal dalam penggunaan alat serta jumlah tenaga kerja yang dibutuhkan.

Penafsiran analisis biaya pemanenan dan produktivitas kayu yang akan diteliti berlokasi di Hutan Produksi Hutan Tanaman Industri PT. PSPI Distrik Petapahan. PT. PSPI Distrik Petapahan memiliki kawasan seluas 20.025 hektar dimana kawasan yang dapat dikelola hanya sekitar 5.800 hektar. Penelitian ini dilakukan untuk menganalisis biaya yang dibutuhkan saat kegiatan pemanenan, yang dimulai dari penebangan, pembagian batang, penumpukan, pengupasan, penyaradan dan pemuatan serta menganalisis produktivitas pemanenan kayu di HTI PT. PSPI Distrik Petapahan.

Rumusan masalah pada penelitian ini adalah seberapa besar biaya pemanenan yang dikeluarkan dan seberapa besar produktivitas kayu yang dihasilkan di HPHTI PT.PSPI Distrik Petapahan. Tujuan penelitian ini untuk menganalisis biaya pemanenan yang dimulai dari penebangan, pembagian batang, penumpukan, pengupasan, penyaradan dan pemuatan serta menganalisis produktivitas kayu dari kegiatan pemanenan di HPHTI PT.PSPI Distrik Petapahan.

\section{METODE PENELITIAN}

Penelitian dilakukan di Hutan Produksi Hutan Tanaman Industri PT.Perawang Sukses Perkasa Industri Distrik Petapahan yang berlokasi di Kabupaten Kampar Provinsi Riau. Penelitian ini dilaksanakan selama 2 bulan, yaitu pada bulan Mei - Juni 2019.

Alat yang digunakan pada penelitian ini yaitu kamera untuk dokumentasi kegiatan pemanenan, stopwatch untuk menghitung 
lamanya waktu setiap kegiatan, phiband untuk mengukur diameter kayu, pita ukur untuk mengukur panjang kayu ekaliptus dan laptop yang memiliki software Microsoft Excel untuk mengolah data. Bahan yang digunakan dalam penelitian ini adalah tally sheet, tegakan ekaliptus berumur 5 tahun yang sedang ditebang/dipanen dan peta areal kerja HPHTI PT.PSPI Distrik Petapahan.

Dalam penelitian ini, pengambilan contoh dilakukan pada tegakan ekaliptus pada umur 5 tahun yang sedang dipanen. Pada pengambilan unit contoh yang terpilih akan dilakukan pengamatan serta penghitungan volume kayu, lamanya waktu kerja alat serta lama kerja pemanenan yang dimulai dari penebangan sampai pada pengangkutan. Penentuan contoh pada penelitian ini menggunakan metode purposive sampling. Dikarenakan terbatasnya jumlah tenaga kerja, biaya serta waktu dalam melaksanakan penelitian ini, maka sampel yang digunakan dalam penelitian ini sebanyak 100 pohon ekaliptus.

Data yang diperoleh pada kegiatan pemanenan di lapangan seperti diameter pangkal sampai ujung kayu dan panjang kayu untuk menghitung produktivitas produksi kayu ekaliptus. Sedangkan untuk analisis biaya pemanenan, data yang diperoleh dari lapangan ialah lama kerja alat per hari dan lama kerja pemanenan yang dimulai dari penebangan sampai pada pengangkutan menggunakan stopwatch. Untuk pengolahan data di lapangan, maka digunakan rumus sebagai berikut.

a. Analisis Biaya

Biaya Tetap

a.1 Biaya Penyusutan

dimana:

$$
D=\frac{M-R}{N x t}
$$

D : Penyusutan (Rp/jam)

$\mathrm{M}$ : Investasi alat (Rp)

$\mathrm{R}$ : Nilai sisa alat pada akhir umur ekonomis $10 \%(\mathrm{Rp})$

$\mathrm{N}$ : Umur ekonomis alat (tahun atau jam) $\mathrm{t}$ : Waktu kerja alat dalam setahun (jam/tahun)

Sumber: (Sitohang, 2016)

a.2 Biaya Bunga Modal

$$
B=\frac{\left[\frac{(M-R)(N+1)}{2}+R\right] x 0,0 p}{N x t}
$$

dimana:

B : Bunga modal (Rp/jam)

0,0p : suku bunga/tahun (18\%)

Sumber: (Sitohang, 2016)

a.3 Biaya Pajak

$$
P j=\frac{\left[\frac{(M-R)(N+1)}{2 N}+R\right] x 0,05}{t}
$$

dimana:

$\mathrm{Pj} \quad$ : Pajak (Rp/jam)

0,05 : Persentase pajak (5\%)

Sumber: (Sitohang, 2016) 
a.4 Biaya Asuransi

$$
A=\frac{\left[\frac{(M-R)(N+1)}{2 N}+R\right] x 0,05}{t}
$$

dimana:

A : Asuransi (Rp/jam)

0,05 :Persentase asuransi (5\%)

Sumber: (Sitohang, 2016)

a.5 Jumlah Biaya Tetap

$$
\mathrm{BT}=\mathrm{D}+\mathrm{B}+\mathrm{Pj}+\mathrm{A}
$$

\section{B. Biaya Variabel}

b.1 Biaya Pemeliharaan (BPr)

Biaya pemeliharaan dalam satuan (Rp/jam) yang dimaksud adalah sebagai upaya untuk menjaga keragaan alat yang dihitung dengan cara membagi besarnya biaya yang dikeluarkan selama satu tahun dengan jam kerja peralatan per tahun, sehingga diperoleh rata-rata biaya pemeliharaan alat per jam.

$$
\text { b.2 Biaya Bahan Bakar }
$$

\section{$B B k$}

$=\frac{\sum \text { pemakaian bahan bakar }(L) x \mathrm{Harga} / L}{\text { Waktu kerja alat }(\mathrm{jam})}$

dimana:

Bbk : biaya bahan bakar (Rp/jam)

Sumber: Mujetahid (2009) dalam (Sitohang, 2016)

\section{b.3 Biaya Oli dan Pelumas (BO)}

$B o=\frac{\text { Jumlah pemakaian oli dan pelumas }(L) x \frac{\text { Harga }}{\text { Liter }}}{\text { Waktu kerja alat }(j a m)}$

dimana:

Bo : Biaya oli dan pelumas (Rp/jam)

Sumber: (Sitohang, 2016)

$$
\begin{aligned}
& \text { b.4 Upah Tenaga Kerja } \\
& \mathbf{U P}=\frac{\boldsymbol{G} \boldsymbol{a j i}(\boldsymbol{R} \boldsymbol{p} \text { per bulan })}{\boldsymbol{H} \boldsymbol{r} \boldsymbol{x} \boldsymbol{W}}
\end{aligned}
$$

dimana:

UP : Upah tenaga kerja (Rp/jam)

$\mathrm{Hr}$ : Hari kerja rata-rata per bulan

W : Jam kerja per hari (jam/hari)

Sumber: (Sitohang, 2016)

b.5 Jumlah Biaya Variabel

$$
\mathrm{BV}=\mathrm{BPr}+\mathrm{Bbk}+\mathrm{Bo}+\mathrm{UP}
$$

Sumber: (Sitohang, 2016)

2. Produktivitas Kayu

a. Volume Kayu

$$
\mathrm{V}=1 / 4 \pi \mathrm{d}^{2 \mathrm{x}} \mathrm{L}
$$

dimana:

$\mathrm{V} \quad$ : Volume kayu $\left(\mathrm{m}^{3}\right)$

$\pi \quad$ :phi $(3,14)$

d : diameter kayu rata-rata (m) : diameter pangkal $(m)+$ diameter ujung $(m)$

L : panjang kayu (m)

Sumber: (Basari, 2004)

b. Perhitungan Produktivitas

dimana:

$$
\mathrm{P}=\frac{\mathrm{V}}{\mathrm{W}}
$$

$\mathrm{P} \quad$ : Produktivitas $\left(\mathrm{m}^{3} / \mathrm{jam}\right)$

$\mathrm{V} \quad$ : Volume kayu $\left(\mathrm{m}^{3}\right)$

W : Waktu efektif (jam)

Sumber: (Basari, 2004) 


\section{HASIL DAN PEMBAHASAN}

\section{A. Analisis Biaya Pemanenan}

\section{Biaya Tetap}

Biaya tetap merupakan biaya yang totalnya tidak berubah-ubah (tetap) walaupun jumlah produksi yang dihasilkan berubah-ubah. Dalam kegiatan pemanenan di HPHTI PT. PSPI Distrik Petapahan

Tabel 1. Biaya Tetap

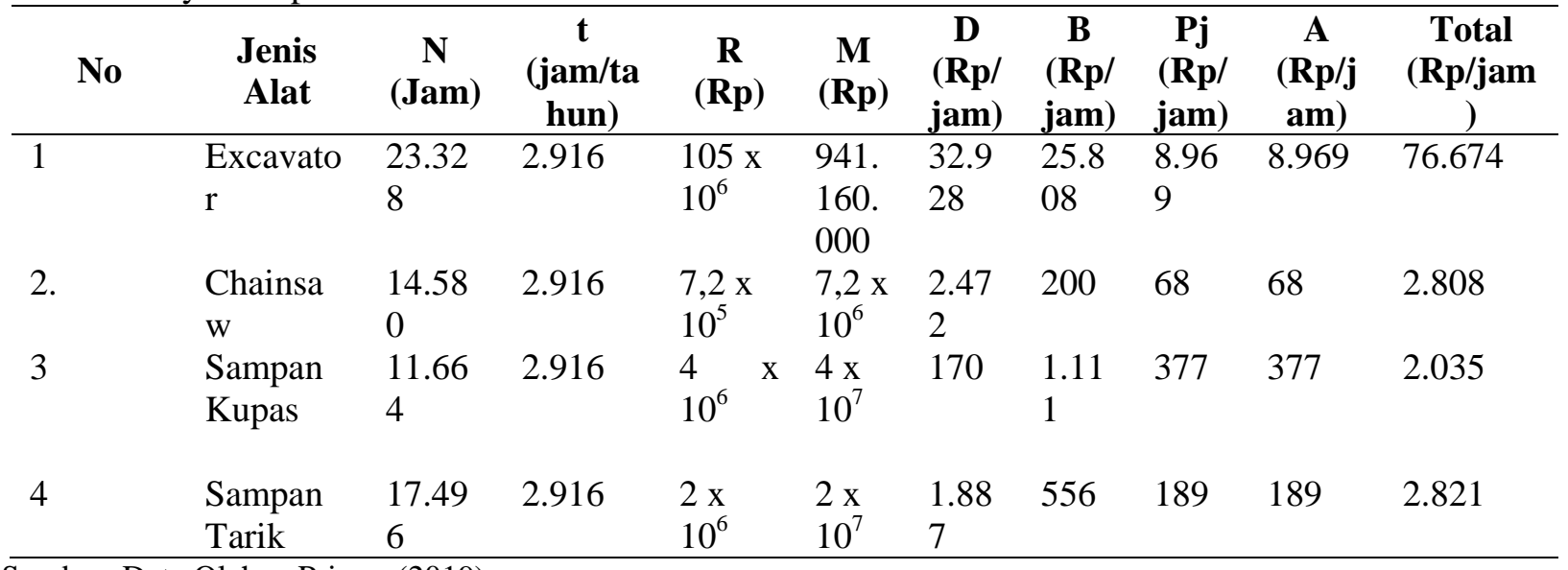

Sumber: Data Olahan Primer (2019)

Dari perhitungan biaya tetap pada kegiatan pemanenan, jumlah biaya tetap untuk excavator Hitachi adalah $\mathrm{Rp}$ 76.675/jam, Rp 2.807/jam untuk chainsaw Stihl, Rp 2.036 dan Rp 2.820 untuk sampan kupas dan sampan tarik. Untuk keseluruhan alat tersebut, maka total biaya tetap adalah Rp 84.339/ jam atau sama dengan Rp 245.932.889/tahun. Jika dibandingkan komponen-komponen yang termasuk dalam biaya tetap diantaranya adalah: biaya penyusutan alat yang digunakan, biaya bunga modal, biaya pajak dan biaya asuransi. Adapun rincian-rincian mengenai biaya tetap di PT. PSPI Distrik Petapahan dapat dilihat pada tabel 1 . 
sedangkan pada penelitian ini untuk kegiatan kupas kulit hanya menggunakan sampan kupas dan excavator dengan biaya tetap yang dikeluarkan untuk kupas kulit adalah $\mathrm{Rp}$ 78.709/jam. Kemudian apabila hasil penelitian ini dibandingkan dengan hasil penelitian Basari (2004), biaya tetap yang dikeluarkan pada penelitian tersebut adalah Rp 357.547, maka biaya penelitian ini jauh lebih rendah atau lebih kecil dibandingkan dengan penelitan sebelumnya. Hal tersebut dikarenakan alat untuk kegiatan penyaradan kayu yang digunakan pada penelitian tersebut adalah traktor, dimana biaya penyusutan traktor tersebut sebesar $\mathrm{Rp}$ 316.800/jam. Dan apabila penelitian ini dibandingkan dengan penelitian (Septian Faqih, Gusti Hardiansyah, 2018), dimana total biaya tetap yang dikeluarkan sebesar Rp 478.333/jam. Total biaya tetap pada penelitian tersebut jauh lebih mahal dibandingkan dengan penelitian ini. Hal tersebut mungkin dapat terjadi karena jenis tanaman yang dipanen pada penelitian tersebut adalah akasia mangium dan jenis areal pada petak tersebut adalah dryland (lahan basah), sehingga jenis alat yang digunakan pada pemanenan juga berbeda.

\section{Biaya Variabel}

Biaya variabel merupakan biaya yang totalnya berubah-ubah sesuai dengan jumlah produksi yang dihasilkan. Pada kegiatan pemanenan di HPHTI PT. PSPI Distrik Petapahan yang termasuk biaya variabel yaitu biaya pemeliharaan, biaya bahan bakar, biaya oli dan pelumas serta upah tenaga kerja. Adapun rincian-rincian biaya variabel yang dikeluarkan oleh PT. PSPI Distrik Petapahan untuk kegiatan pemanenan dapat dilihat pada tabel 2 . 
Tabel 2. Biaya Variabel

\begin{tabular}{|c|c|c|c|c|c|c|}
\hline No & Jenis Alat & $\begin{array}{c}\text { Biaya } \\
\text { Pemeliharaan } \\
\text { (Rp/jam) }\end{array}$ & $\begin{array}{c}\text { Biaya Bahan } \\
\text { Bakar } \\
\text { (Rp/jam) }\end{array}$ & $\begin{array}{c}\text { Biaya Oli } \\
\text { dan Pelumas } \\
(\text { Rp/jam) }\end{array}$ & $\begin{array}{c}\text { Upah Tenaga } \\
\text { Kerja } \\
(\text { Rp/jam) }\end{array}$ & $\begin{array}{c}\text { Total } \\
\text { (Rp/jam) }\end{array}$ \\
\hline 1 & $\begin{array}{l}\text { Excavator } \\
\text { Hitachi }\end{array}$ & 3.888 & 93.500 & 3.888 & 22.634 & 123.910 \\
\hline $\begin{array}{l}2 \\
3 \\
4\end{array}$ & $\begin{array}{l}\text { Chainsaw Stihl } \\
\text { Sampan Kupas } \\
\text { Sampan Tarik }\end{array}$ & $\begin{array}{c}5.737 \\
1.372 \\
686\end{array}$ & 4.722 & 679 & 13.289 & $\begin{array}{c}24.427 \\
1.372 \\
686\end{array}$ \\
\hline & Total & 11.682 & 98.222 & 118.404 & 35.923 & 150.395 \\
\hline
\end{tabular}

Sumber: Data Olahan Primer (2019)

Dari keseluruhan komponen biaya yang dihitung, maka total biaya variabel yang dikeluarkan adalah $\mathrm{Rp}$ 62.142.800/bulan atau sekitar Rp 255.732/jam. Apabila dibandingkan dengan total biaya variabel pada penelitian Sitohang (2016), total biaya variabel pada penelitian ini lebih kecil dibandingkan pada penelitian sebelumnya, dimana pada penelitian Sitohang (2016) total biaya variabel yang dikeluarkan adalah $\mathrm{Rp}$ 398.849,38/jam. Sama halnya pada biaya tetap, adanya perbedaan atau selisih pada biaya variabel dikarenakan alat untuk kupas kulit berbeda pada penelitian yang dilakukan pada studi kasus yang berbeda.

\section{B. Produktivitas Pemanenan}

\section{Penebangan}

Penebangan merupakan kegiatan awal dalam pemanenan kayu dengan tujuan untuk menghasilkan bahan baku kayu industri. Dalam kegiatan pemanenan ada beberapa hal yang perlu diperhatikan, seperti topografi atau kelerengan lahan. Hal tersebut dapat berpengaruh terhadap hasil dari penebangan, karena apabila operator chainsaw tidak memahami kondisi topografi maka hasil dari penebangan tidak efisien. Hasil dari kegiatan penebangan dapat dilihat pada gambar 1 . Berdasarkan penghitungan dari 100 sampel pohon, maka diperoleh total volume kayu adalah $11,41 \mathrm{~m}^{3}$, dimana volume terbesar dari 100 pohon contoh adalah $0,21 \mathrm{~m}^{3}$ dan volume terkecil adalah $0,06 \mathrm{~m}^{3}$. 


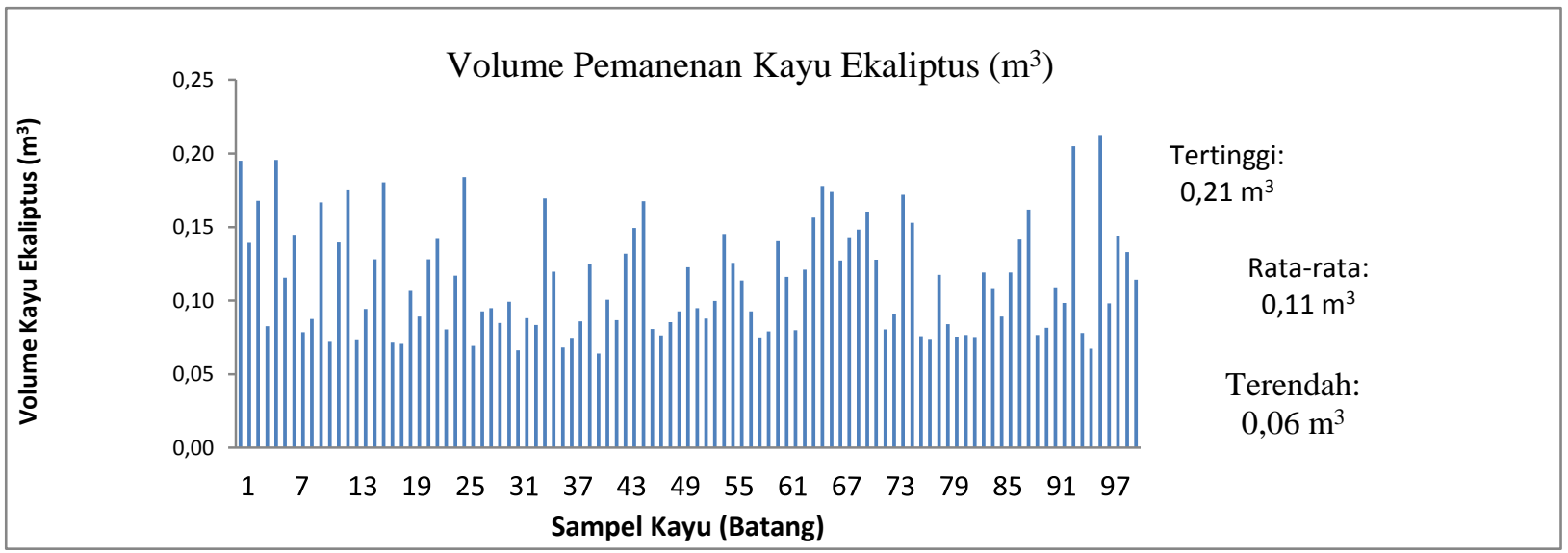

Gambar 1. Volume Kayu Ekaliptus Sumber: Data Olahan Primer (2019)

Apabila dibandingkan dengan penelitian Sitohang (2016), volume pemanenan kayu di hutan tanaman industri pada penelitian ini lebih besar dibandingkan dengan hasil penelitian Sitohang (2016), yaitu terdapat selisih sebesar $0,96 \mathrm{~m}^{3}$. Adanya selisih tersebut dapat disebabkan oleh jumlah sampel pada penelitian Sitohang (2016) sebanyak 80 pohon, sedangkan pada penelitian ini berjumlah 100 pohon. Jika volume penebangan pada penelitian ini dibandingkan dengan penelitian Basari (2004), volume penebangan pada penelitian ini jauh lebih rendah dibandingkan dengan penelitian sebelumnya dimana volume penebangan pada penelitian Basari (2004), sebesar 892,9 $\mathrm{m}^{3}$. Selain perhitungan terhadap volume kayu, dalam kegiatan penebangan ini juga dihitung produktivitas penebangan kayu. Adapun produktivitas penebangan dapat dilihat pada gambar 2 . Berdasarkan pengamatan di lapangan, waktu untuk memotong atau menebang satu batang pohon ekaliptus berkisar antara 6 detik sampai dengan 9 detik. Adanya perbedaan dalam hal waktu potong disebabkan oleh besarnya diameter suatu batang, sehingga semakin besar diameter pohon tersebut maka waktu yang dibutuhkan untuk memotong atau menebang pohon akan lebih lama dibandingkan dengan menebang pohon yang memiliki diameter yang lebih kecil. 


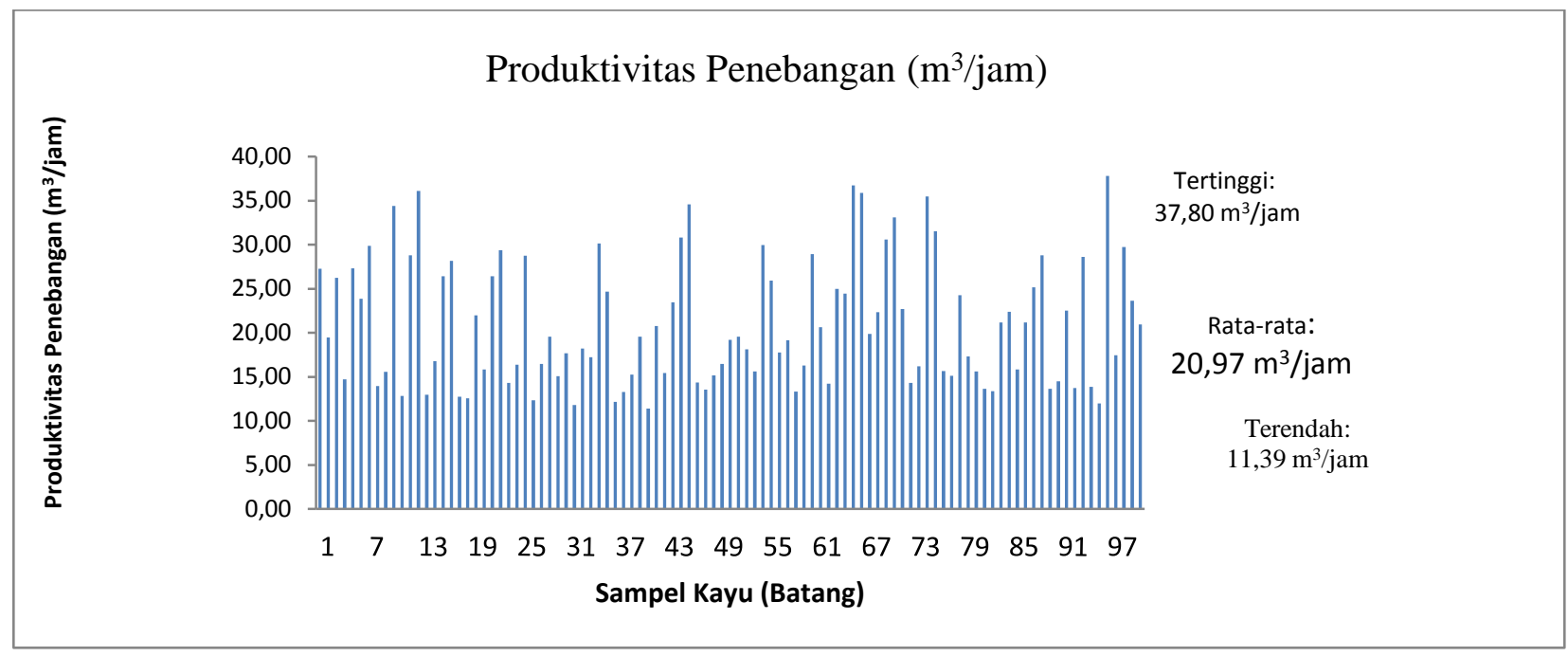

Gambar 2. Produktivitas Penebangan Sumber: Data Olahan Primer (2019)

Produktivitas tertinggi untuk penebangan sebesar $37,80 \mathrm{~m}^{3} / \mathrm{jam}$ dan terendah sebesar $11,39 \mathrm{~m}^{3} / \mathrm{jam}$, sehingga diperoleh rata-rata produktivitas penebangan adalah 20,97 $\mathrm{m}^{3} / \mathrm{jam}$. Besarnya produktivitas pada penelitian ini lebih kecil dibandingkan dengan penelitian Sitohang (2016), dimana produktivitas penebangan yang diperoleh sebesar 77,91 $\mathrm{m}^{3} / \mathrm{jam}$. Adanya selisih sebesar $56,94 \mathrm{~m}^{3} / \mathrm{jam}$ dikarenakan pada penelitian sebelumnya waktu hilang tidak dihitung, sementara pada penelitian ini komponen waktu yang dihitung pada saat penebangan adalah waktu potong, waktu persiapan dan waktu hilang.

\section{Penumpukan Kayu}

Penumpukan kayu merupakan suatu kegiatan yang dilakukan untuk menumpuk kayu setelah ditebang menjadi beberapa tumpukan kayu yang rapi. Berdasarkan hasil pengamatan di lapangan, kegiatan menumpuk kayu yang dilakukan di lapangan menghabiskan waktu sekitar 32 menit 45 detik dengan produktivitas menumpuk kayu sebesar $21,10 \mathrm{~m}^{3} / \mathrm{jam}$ atau rata-rata menumpuk kayu sebesar $0,21 \mathrm{~m}^{3} / \mathrm{jam}$ untuk 100 batang ekaliptus. Apabila waktu untuk menumpuk 100 kayu ekaliptus atau 351 sortimen kayu sekitar 32 menit 45 detik, maka rata-rata untuk menumpuk 1 sortimen kayu adalah 25,52 detik. Jika dibandingkan dengan hasil penelitian Sitohang (2016), 
waktu menumpuk pada penelitian ini lebih cepat 17,34 detik.

Produktivitas penumpukan kayu dapat dilihat pada gambar 3.

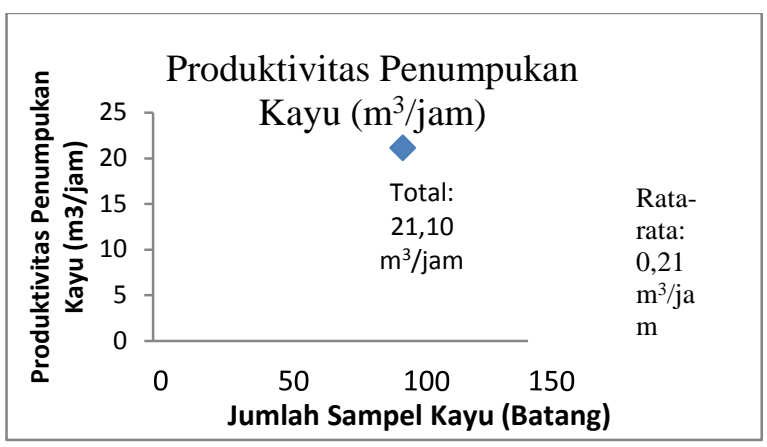

Gambar 3. Produktivitas Penumpukan Kayu Sumber: Data Olahan Primer (2019)

\section{Pembagian Batang}

Pembagian batang merupakan kegiatan untuk memotong kayu dengan panjang yang sesuai dengan standar yang telah ditetapkan. Untuk saat ini standar panjang kayu yang digunakan oleh PT.PSPI Distrik Petapahan adalah 4 meter, dan panjang kayu minimal yang diperbolehkan dibawa ke mill adalah 2,5 meter. Adapun produktivitas pembagian batang dapat dilihat pada gambar 4 . Berdasarkan hasil pengamatan di lapangan waktu yang diperlukan untuk memotong atau membagi batang ekaliptus menjadi ukuran yang telah ditetapkan membutuhkan waktu sekitar 3 sampai 4 detik per potongan, sehingga untuk satu batang ekaliptus dapat dibagi menjadi 3 sampai 4 bagian sesuai dengan panjang kayu. Sehingga dari 100 batang ekaliptus yang dijadikan sebagai sampel diperoleh total waktu untuk pembagian batang sebesar 1.151 detik atau sekitar 19,18 menit.

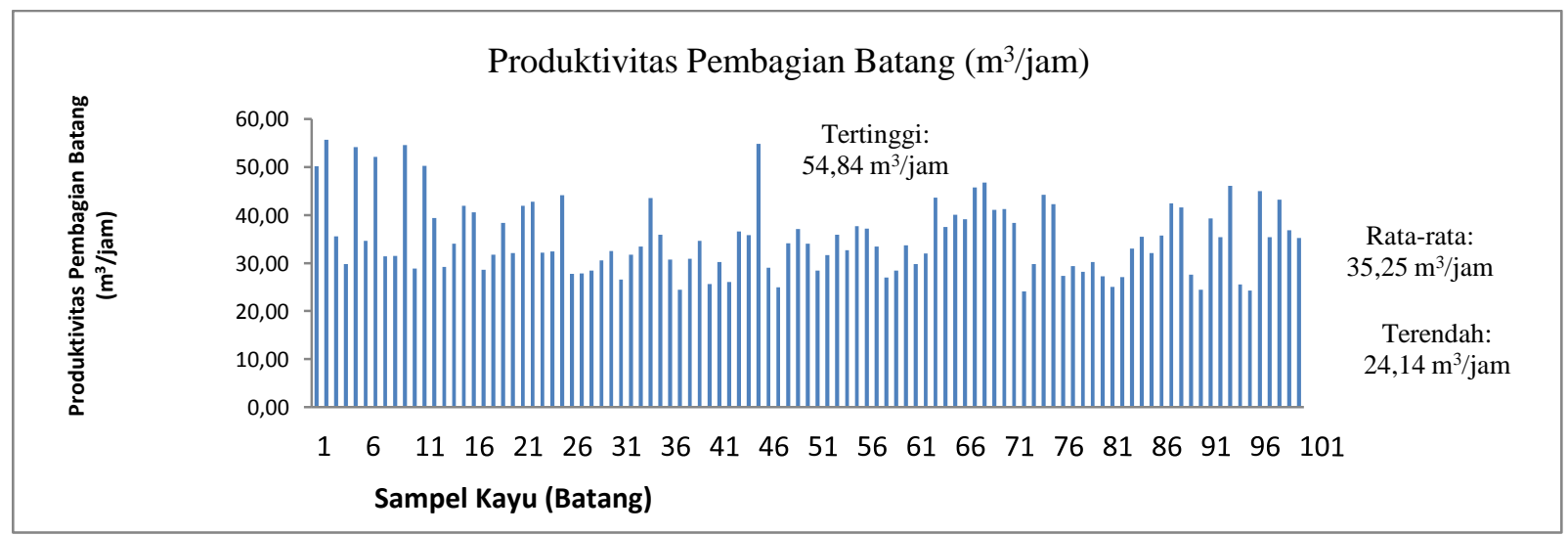

Gambar 4. Produktivitas Pembagian Batang

Sumber: Data Olahan Primer (2019) 
Besarnya produktivitas pembagian batang adalah 35,25 $\mathrm{m}^{3} / \mathrm{jam}$, dimana produktivitas tertinggi sebesar $54,84 \mathrm{~m}^{3} / \mathrm{jam}$ dan terendah sebesar 24,14 $\mathrm{m}^{3} / \mathrm{jam}$ dengan jumlah sortimen yang dihasilkan adalah 351 batang. Dibandingkan dengan penelitian Sitohang (2016) dimana produktivitas pembagian batang hanya sebesar $12,30 \mathrm{~m}^{3} / \mathrm{jam}$. Rendahnya produktivitas pembagian batang pada penelitian tersebut dibandingkan dengan penelitian ini dikarenakan jumlah sampel yang digunakan lebih kecil dan panjang sortimen yang digunakan pada peneltiian tersebut hanya sepanjang 2,50 meter, sehingga waktu untuk pembagian batang lebih lama jika dibandingkan dengan penelitian ini.

\section{Pengupasan Kulit}

Pada kegiatan ini kulit pada batang ekaliptus dipisahkan dari batang dengan cara memasukkan batang ekaliptus ke dalam sampan kupas (sampan goreng), kemudian kayu tersebut dilepaskan kulitnya dengan bantuan excavator. Untuk mengupas kulit ekaliptus membutuhkan waktu yang berbeda-beda tergantung pada banyaknya batang ekaliptus yang dimasukkan dalam sampan kupas. Berdasarkan hasil pengamatan di lapangan, pengupasan kulit untuk 100 batang ekaliptus dilakukan sebanyak 4 tahap. Maka dari hasil pengamatan di lapangan dan perhitungan, untuk 100 batang ekaliptus yang dijadikan sebagai sampel membutuhkan waktu untuk mengupas kulit sekitar 17 menit 33 detik atau sama dengan 0,29 jam dengan produktivitas yang dihasilkan 39,50 $\mathrm{m}^{3} / \mathrm{jam}$, dengan produktivitas terendah sebesar 8,04 $\mathrm{m}^{3} /$ jam dan tertinggi $12,31 \mathrm{~m}^{3} / \mathrm{jam}$. Produktivitas pengupasan kulit dapat dilihat pada gambar 5 .

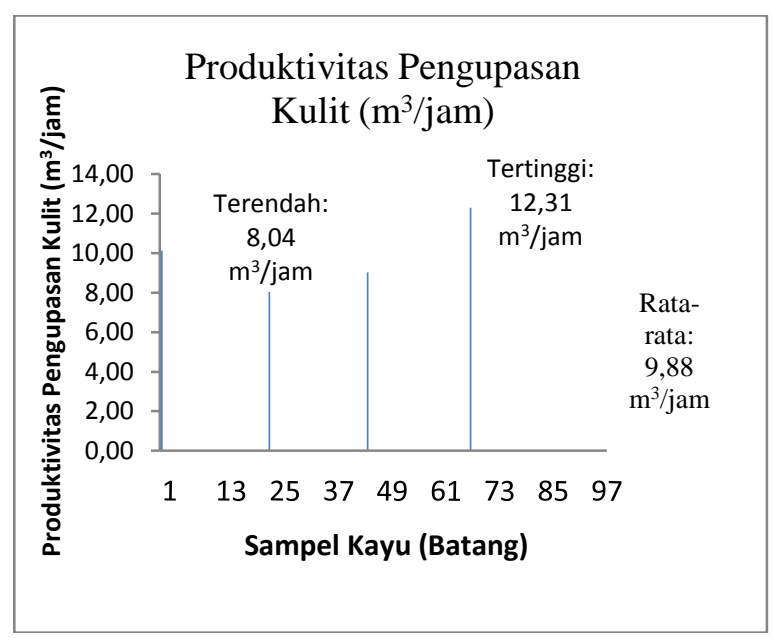

Gambar 5. Produktivitas Pengupasan Kulit Sumber: Data Olahan Primer (2019)

$$
\text { Sitohang (2016) menyatakan }
$$

produktivitas kupas kulit pada penelitian tersebut adalah 20,01 $\mathrm{m}^{3} / \mathrm{jam}$, dimana terdapat selisih sebesar 1,97 $\mathrm{m}^{3} / \mathrm{jam}$. Perbedaan hasil produktivitas ini bisa disebabkan oleh jenis alat yang digunakan berbeda, dimana pada penelitian Sitohang (2016) kegiatan kupas kulit menggunakan alat debarker, sedangkan pada penelitian ini 
pengupasan kulit menggunakan sampan kupas dan excavator.

\section{Penyaradan}

Penyaradan merupakan proses pemindahan kayu yang telah dikupas dari dalam areal hutan (in field) menuju TPn (tempat pengumpulan kayu sementara). Pemindahan kayu ini dilakukan untuk mempermudah pada saat proses pemuatan kayu ke atas truk (loading to truck). Penyaradan kayu dilakukan dengan menggunakan sampan tarik, dimana sortimen-sortimen (potongan kayu) dimuat ke atas sampan tarik kemudian sampan tersebut akan ditarik dengan bantuan excavator menuju TPn. Berdasarkan hasil penelitian di lapangan, penyaradan sortimen kayu ekaliptus sebanyak 351 potong memerlukan waktu sekitar 32 menit 24 detik dengan produktivitas yang dihasilkan sebesar 21,23 $\mathrm{m}^{3} / \mathrm{jam}$ dengan rata-rata produktivitas sebesar $0,21 \mathrm{~m}^{3} / \mathrm{jam}$. Berdasarkan hasil penelitian Purba (2018), rata-rata untuk produktivitas penyaradan sebesar 32,6 $\mathrm{m}^{3} / \mathrm{jam}$. Jika dibandingkan dengan penelitian ini, rata-rata produktivitas penyaradan pada penelitian Purba (2018), lebih besar sekitar 11,37 $\mathrm{m}^{3} / \mathrm{jam}$. Produktivitas penyaradan dapat dilihat pada gambar 6.

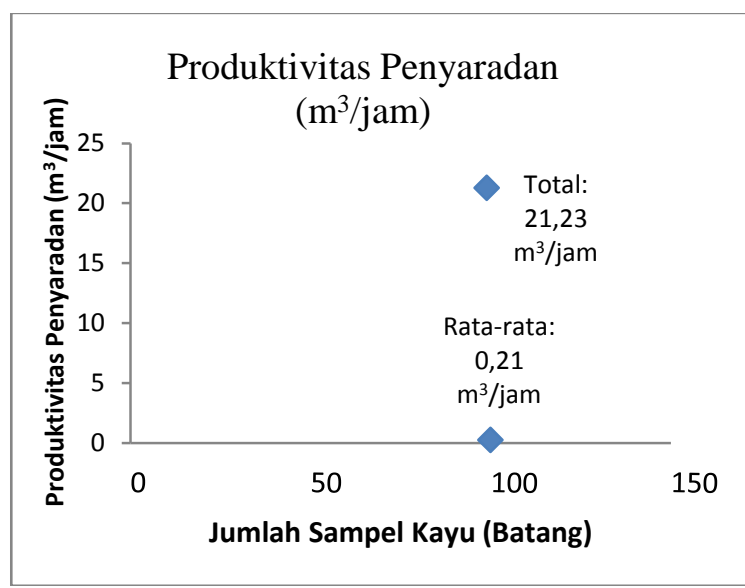

Gambar 6. Produktivitas Penyaradan Sumber: Data Olahan Primer (2019)

Adanya selisih sebesar 22,095 $\mathrm{m}^{3} / \mathrm{jam}$ dikarenakan pada saat penelitian jalan yang berada di sekitar lokasi penelitian kurang bagus, sehingga hal tersebut memperlambat proses penyaradan. Selain itu lamanya waktu pada penyaradan dikarenakan jarak antara in field menuju tepi jalan yang cukup jauh serta kondisi jalan yang licin. Selain disebabkan jarak dan kondisi jalan, waktu penyaradan juga dipengaruhi oleh banyaknya sortimen yang dimuat ke atas sampan tarik. 


\section{Bongkar Muat Sarad}

Setelah sortimen ekaliptus disarad dari lokasi penebangan kayu menuju tepi jalan, maka langkah selanjutnya adalah bongkar muat sarad. Bongkar muat sarad merupakan kegiatan dimana sortimen-sortimen yang berada di alat sarad dikeluarkan dari TPn kemudian disusun di TPK (Tempat Pengumpulan Kayu). Pada proses bongkar muat sarad menggunakan alat bantu excavator untuk menyusun sortimen ekaliptus. Berdasarkan hasil perhitungan dapat dilihat bahwa proses bongkar muat sarad untuk 100 batang ekaliptus (351 sortimen) membutuhkan waktu sekitar 13,54 menit atau sama dengan 8 detik per sortimen. Dari lamanya waktu yang dihabiskan untuk 100 batang ekaliptus, maka diperoleh produktivitas sebesar 49,61 $\mathrm{m}^{3} /$ jam atau rata-rata bongkar muat sarad sebesar $0,50 \mathrm{~m}^{3} / \mathrm{jam}$. Produktivitas bongkar muat sarad dapat dilihat pada gambar 7 .

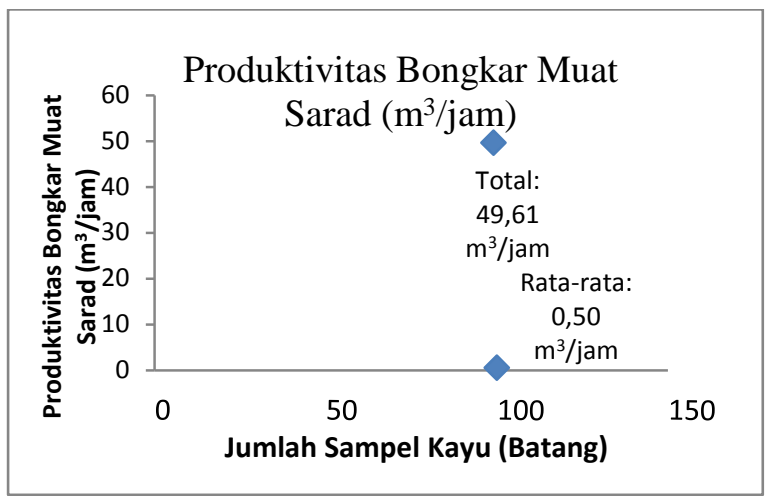

Gambar 7. Produktivitas Bongkar Muat Sarad Sumber: Data Olahan Primer

\section{Pemuatan ke Truk}

Tahapan terakhir pada pemanenan di areal tanah kering (dry land) adalah loading to truck (muat kayu). Pada tahapan ini kayu yang berada di TPK dimuat ke atas truk, yang nantinya potongan kayu tersebut dibawa ke pabrik. Truk yang digunakan untuk mengangkut kayu dibagi menjadi 2 jenis, yaitu tronton dan trinton. Tronton merupakan truk yang memiliki 2 stik dan dapat memuat kayu sekitar 25 - 30 ton kayu, sedangkan trinton merupakan truk yang memiliki 3 stik dan dapat memuat kayu sekitar 35 - 40 ton kayu sehingga muatannya lebih besar dibandingkan dengan tronton. Berdasarkan hasil pengamatan di lapangan, proses pemuatan ke truk membutuhkan waktu sekitar 55 menit 15 detik untuk 100 
batang ekaliptus atau 351 potongan kayu. Lamanya waktu tersebut dikarenakan clone ekaliptus yang sedang dipanen merupakan clone yang kurang bagus (clone EP0497AA), sehingga batang yang dihasilkan bengkok (tidak lurus seperti pada batang ekaliptus umumnya), sehingga pada saat muat kayu memerlukan waktu yang cukup lama untuk menyusun tiap kayu di atas truk. Produktivitas pemuatan ke truk dapat dilihat pada gambar 8 .

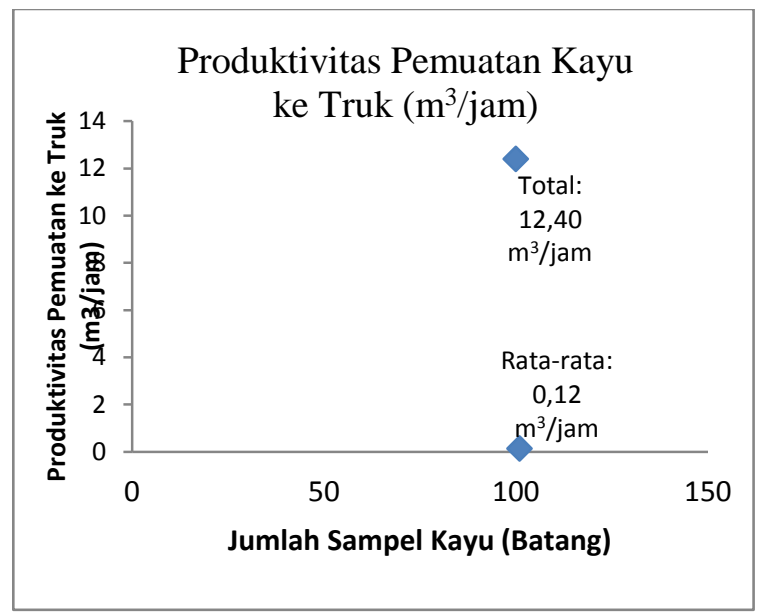

Gambar 8. Produktivitas Pemuatan ke Truk Sumber: Data Olahan Primer (2019)

Dari lamanya waktu muat kayu, maka dihasilkan produktivitas pemuatan ke truk sekitar 12,40 $\mathrm{m}^{3} / \mathrm{jam}$. Jika dibandingkan dengan hasil penelitian Sitohang (2016), produktivitas pemuatan ke truk pada penelitian tersebut adalah 48,16 $\mathrm{m}^{3} / \mathrm{jam}$ untuk truk 1 yang diamati, sehingga dapat dikatakan bahwa produktivitas pemuatan ke truk pada penelitian Sitohang (2016) lebih besar dibandingkan dengan penelitian ini.

\section{Rekapitulasi Produktivitas Pemanenan}

Dari hasil pengamatan di lapangan dan hasil perhitungan yang telah peneliti lakukan di HTI PT. PSPI Distrik Petapahan, ada 7 komponen yang diperhatikan dalam aspek produktivitas pemanenan yaitu penebangan, pembagian batang. penumpukan, pengupasan, penyaradan, bongkar muat sarad dan pemuatan ke truk. Adapun rekapitulasi produktivitas masing-masing kegiatan dapat dilihat pada tabel 3. 
Tabel 3. Rekapitulasi Produktivitas Pemanenan

\begin{tabular}{llcc}
\hline No. & \multicolumn{1}{c}{ Kegiatan } & Waktu (menit) & Produktivitas ( $\left.\mathbf{m}^{3} / \mathbf{j a m}\right)$ \\
\hline 1 & Penebangan & 24,45 & 20,97 \\
2 & Penumpukan & 32,45 & 21,10 \\
3 & Pembagian Batang & 19,18 & 35,25 \\
4 & Pengupasan & 17,33 & 39,50 \\
5 & Penyaradan & 32,24 & 21,23 \\
6 & Bongkar Muat Sarad & 13,54 & 49,61 \\
7 & Pemuatan ke Truk & 55,15 & 12,40 \\
& Total & 194,34 & 197,06
\end{tabular}

Sumber: Data Olahan Primer (2019)

Berdasarkan hasil perhitungan pada tabel 3, dapat diketahui bahwa waktu total dalam kegiatan pemanenan dengan 100 sampel pohon ekaliptus adalah 194 menit 34 detik. Dari keseluruhan kegiatan tersebut, kegiatan yang memerlukan waktu paling lama adalah pada saat pemuatan (loading to truck) yang mencapai waktu 55 menit 15 detik. Hal ini dikarenakan clone yang sedang dipanen merupakan clone yang kurang bagus, sehingga batang ekaliptus yang dihasilkan bengkok dan hal ini berdampak pada lamanya penyusunan kayu ke atas truk. Dari hasil perhitungan juga dapat diluhat bahwa dari 7 kegiatan dalam pemanenan, waktu tercepat adalah pada saat bongkar muat sarad dimana waktu yang diperlukan sekitar 13 menit 54 detik.

Untuk produktivitas dari kegiatan pemanenan, total keseluruhan produktivitas adalah 197,06 $\mathrm{m}^{3} / \mathrm{jam}$, dimana produktivitas tertinggi sebesar 49,61 $\mathrm{m}^{3} / \mathrm{jam}$ (bongkar muat sarad) dan terendah sebesar 12,40 $\mathrm{m}^{3} /$ jam (pemuatan ke truk).

\section{Analisis Biaya Pemanenan pada Setiap}

\section{Kegiatan Pemanenan}

Dari keseluruhan biaya tetap dan biaya variabel yang telah dikeluarkan oleh pihak perusahaan untuk kegiatan pemanenan, maka dapat dihitung dan dianalisis biaya pemanenan untuk setiap kegiatan. Analisis biaya pemanenan dapat dilihat pada tabel 4 
Tabel 4. Analisis Biaya Pemanenan untuk Setiap Kegiatan Pemanenan

\begin{tabular}{|c|c|c|c|c|}
\hline No & Nama Kegiatan & $\begin{array}{c}\text { Produktivitas } \\
\left(\mathbf{m}^{3} / \mathbf{j a m}\right)\end{array}$ & $\begin{array}{c}\text { Biaya Variabel } \\
+ \text { Biaya Tetap } \\
\text { (Rp/jam) }\end{array}$ & $\begin{array}{c}\text { Jenis Alat yang } \\
\text { digunakan }\end{array}$ \\
\hline 1. & Penebangan & 20,97 & \multirow{2}{*}{27.235} & \multirow{2}{*}{ Chainsaw } \\
\hline 2. & Pembagian Batang & 35,25 & & \\
\hline 3. & Penumpukan & 21,10 & 200.584 & \multirow{3}{*}{$\begin{array}{l}\text { Excavator } \\
\text { Excavator dan } \\
\text { Sampan Kupas } \\
\text { Excavator dan } \\
\text { Sampan Tarik }\end{array}$} \\
\hline 4. & Pengupasan Kulit & 39,50 & 203.991 & \\
\hline 5. & Penyaradan & 21,23 & 204.091 & \\
\hline $\begin{array}{l}6 . \\
7 .\end{array}$ & $\begin{array}{l}\text { Bongkar Muat Sarad } \\
\text { Pemuatan ke truk }\end{array}$ & $\begin{array}{l}49,61 \\
12,40\end{array}$ & 200.584 & \multirow[t]{2}{*}{ Excavator } \\
\hline & Total & & 836.485 & \\
\hline
\end{tabular}

Sumber: Data Olahan Primer (2019)

Dari tabel 4 dapat dilihat bahwa biaya pemanenan yang dikeluarkan untuk pemanenan di hutan tanaman industri berbeda-beda untuk setiap kegiatan. Biaya pemanenan terkecil berada pada kegiatan penebangan dan pembagian batang yaitu $\mathrm{Rp}$ 27.235/jam. Hal ini dikarenakan alat yang digunakan hanya 1 jenis yaitu chainsaw Stihl. Kemudian biaya terbesar pada saat pemanenan adalah pada kegiatan penyaradan, dengan biaya sebesar $\mathrm{Rp}$ 204.091/jam. Besarnya biaya penyaradan dibandingkan dengan biaya pada kegiatan lain disebabkan penggunaan alat saat menyarad kayu menggunakan 2 jenis alat sekaligus, yaitu Excavator Hitachi dan Sampan Tarik. Maka total biaya pemanenan yang dimulai dari penebangan, pembagian batang, penumpukan, pengupasan kulit, penyaradan, bongkar muat sarad dan pemuatan ke truk adalah sebesar $\mathrm{Rp}$ 836.485/jam. Jika dibandingkan dengan penelitian Sitohang (2016), total biaya pemanenan pada penelitian ini lebih besar sekitar Rp 76.476,06/jam. Hal ini dapat terjadi karena pada penelitian tersebut tidak menghitung besarnya produktivitas dan biaya pemanenan untuk kegiatan bongkar muat sarad, serta pada kegiatan kupas kulit hanya menggunakan 1 alat yaitu debarker. Selain itu Purba (2018) mengatakan bahwa biaya produksi pada pemanenan akan lebih rendah apabila excavator yang digunakan adalah excavator Hitachi, karena harga 
pembelian excavator Hitachi lebih rendah dibandingkan dengan excavator Cobelco 210 pc dan standar umur pemakaian excavator Hitachi lebih lama jika dibandingkan dengan excavator Cobelco.

\section{KESIMPULAN}

Berdasarkan hasil penelitian yang telah peneliti lakukan, maka diperoleh kesimpulan pada penelitian ini adalah besarnya biaya produksi untuk pemanenan kayu adalah biaya penebangan sebesar Rp 27.235/jam, biaya pembagian batang sebesar $\mathrm{Rp}$ 27.235/jam, biaya penumpukan batang sebesar Rp 200.584/jam, biaya pengupasan kulit sebesar Rp 203.991/jam, biaya penyaradan sebesar Rp 204.091/jam, biaya bongkar muat sarad sebesar Rp 200.584/jam dan biaya pemuatan ke truk sebesar Rp 200.584/jam.

Sedangkan untuk produktivitas kayu dari kegiatan pemanenan di HPHTI PT. PSPI Distrik Petapahan diperoleh produktivitas penebangan sebesar 20,97 $\mathrm{m}^{3} / \mathrm{jam}$, produktivitas pembagian batang sebesar 35,25 $\mathrm{m}^{3} / \mathrm{jam}$, produktivitas penumpukan batang sebesar $21,10 \mathrm{~m}^{3} / \mathrm{jam}$, produktivitas pengupasan kulit sebesar 39,50 $\mathrm{m}^{3} / \mathrm{jam}$, produktivitas penyaradan sebesar $21,23 \mathrm{~m}^{3} / \mathrm{jam}$, produktivitas bongkar muat sarad sebesar 49,61 $\mathrm{m}^{3} / \mathrm{jam}$ dan produktivitas pemuatan ke truk 12,40 $\mathrm{m}^{3} / \mathrm{jam}$.

\section{DAFTAR PUSTAKA}

Basari, Z. (2004). Analisis Biaya Pemanenan Kayu Bulat Sistem Kemitraan HPH Koperasi Desa Di Kalimantan Tengah. Forest Products Research Journal. https://doi.org/10.20886/jphh.2004.22.2 .113-122

Purba, B. (2018). Analisis Biaya dan Produktivitas Penyaradan Kayu Di Hutan Tanaman Industri PT. Toba Pulp Lestari, Tbk. Sektor Aek Nauli. Universitas Sumatera Utara.

Septian Faqih, Gusti Hardiansyah, E. R. (2018). Analisa Biaya Pemanenan Tanaman Mangium (Acacia Mangium) Di Pt Bina Silva Nusa Kecamatan Batu Ampar Kabupaten Kubu Raya. Jurnal Hutan Lestari, 6, 804-813.

Sitohang, W. (2016). Analisis Biaya Dan Produktivitas Produksi Kayu Pada Hutan Tanaman Industri (Studi Kasus: PT. Sumatera Riang Lestari-Blok I Sei Kebaro, Kabupaten Labuhan Batu Selatan dan Kabupaten Padang Lawas Utara) (vol. 5). Universitas Sumatera Utara. 